\title{
Cautery for lower lid entropion
}

\author{
Hosam T El-Kasaby
}

\begin{abstract}
A prospective study was undertaken to evaluate a simple cautery technique for the correction of involutional lower lid entropion in $\mathbf{5 0}$ patients. After a 12 month follow-up period all patients were free of entropion. Only one patient needed to have the procedure repeated because of recurrence. The technique was found to be simple, effective, safe, and required very little time and skill.
\end{abstract}

(Br F Ophthalmol 1992; 76: 532-533)

A multitude of plastic surgery procedures have been reported to correct lower lid entropion ${ }^{1-6}$ including Ziegler's galvanocautery puncture initially described in $1909 .{ }^{1}$ As many patients with involutional lower lid entropion may be infirm and bed-ridden, it is important that entropion correction can be performed at the bedside. A modification of Ziegler's cautery appeared ideal for this purpose so a prospective study was undertaken.

\section{Materials and methods}

Adults suffering from involutional lower lid entropion attending the Wolverhampton Eye Infirmary were consecutively allocated to take part in this study. Informed consent was obtained in all cases. A total of 50 patients were recruited, 22 females, and 28 males aged 58-86 years (mean age 70 years). Only eight patients had previous entropion surgery.

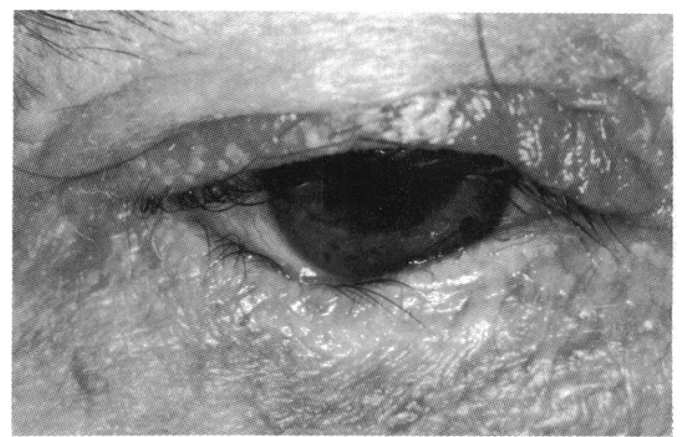

Figure 1 Preoperative lid appearance.

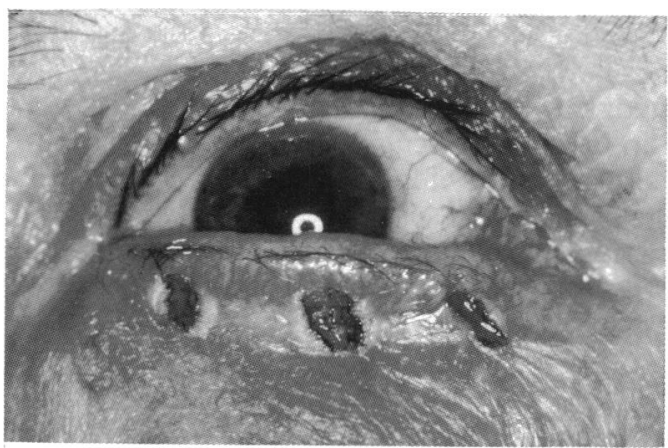

Figure 2 Immediate postoperative appearance.
TECHNIQUE

A local anaesthetic ( $3 \mathrm{ml}$ lignocaine $2 \%$ ) was injected subcutaneously in the lower lid at the inferior orbital margin near the site of emergence of the infraorbital nerve. This site of injection provided adequate anaesthesia to the lower lid and did not result in excess fluid, which not only could make cauterisation difficult and inaccurate, but also might correct the entropion (Fig 1). Topical anaesthetic drops were instilled in the conjunctival sac. The lower lid was grasped near the centre of its margin with toothed forceps and stretched upwards and away from the eye globe. An electric cautery was used, the wire of which was heated to red hot. A hand held battery cautery is not suitable as it does not reach high enough temperatures. Using the cautery tip, three vertical strokes were made in the centre of each third of the lower lid (Fig 2). These strokes started about 1 to $2 \mathrm{~mm}$ from the lid margin and extended to a length of $5 \mathrm{~mm}$. The burns should not reach any deeper than the anterior surface of the tarsal plate. A postoperative dressing was not necessary. Antibiotic ointment was applied to the burns and the patient was asked to use it twice daily for 10 days. The cautery was performed by the same surgeon in all cases (HT E-K).

\section{Results}

All patients were reviewed at 2 and 4 weeks postoperatively. After 2 weeks the lower lids of all patients were in good position; none had

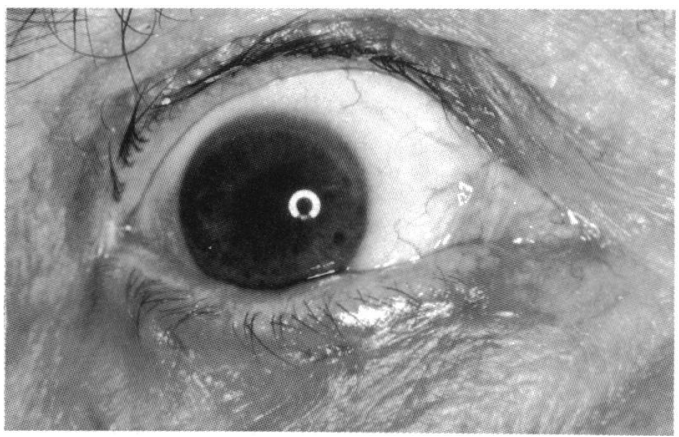

Figure 3 Lid appearance 2 weeks after surgery.

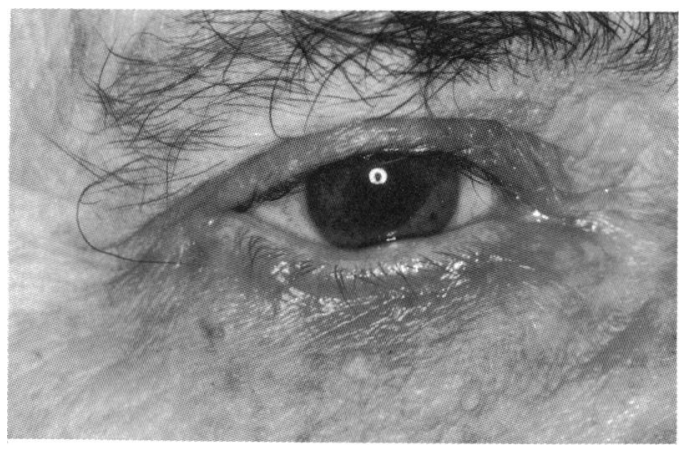

Figure 4 Lid appearance 4 weeks after surgery.
Wolverhampton and Midland Counties Eye Infirmary, Compton Road, Wolverhampton, West Midlands WV3 9QR 
residual entropion or consecutive ectropion. The lower lid at this stage had three small scabs (Fig $3)$. After 4 weeks it was difficult to see the cautery scars (Fig 4). No cases of infection were noted. All 50 lower lids were in a satisfactory cosmetic and functional state. The average follow-up period was 12 months (range 6-17 months), with 45 patients followed-up for more than 12 months. All 50 lids remained free of entropion except one which had a recurrence after 7 months. The same procedure was repeated and 10 months later the lower lid remained free of entropion.

\section{Discussion}

This procedure works through the formation of three small vertical scars which, on healing, contract and consequently evert the lower lid. These scars also interrupt the continuity of the pretarsal part of the orbicularis muscle thus eliminating its spasm which contributes to the entropion. The scars should also prevent upward migration of the preseptal part of the orbicularis muscle to override the pretarsal part. ${ }^{78}$

The procedure described was found to be effective in treating involutional lower lid entropion. After an average follow-up period of 12 months the recurrence rate was minimal. Only one case needed a repeat procedure. A postoperative dressing was not required and postoperative pain was minimal or absent. None of the patients complained about the cosmetic appearance in the immediate or early postoperative period. The procedure requires no sutures and can be easily performed at the bedside.

Lid cautery used as a primary or secondary procedure for the correction of involutional lower lid entropion provides a safe, efficient, and quick method of treatment. The skill required is minimal and the cost is negligible. It is ideal for elderly patients who cannot tolerate lengthy plastic lid procedures, and appears suitable for use in third world countries as the material cost of the procedure is small. However cauterising the skin of black patients might lead to keloid formation and care should be taken.

The author thanks Mr M R Paul, FRCS, FCOphth, for allowing him to publish details of his cases and Mr P Murray, PhD, FRCS FCOphth, for critically reading the manuscript.

1 Ziegler SL. Galvanocautery puncture in ectropion and entropion. FAMA 1909; 53: 183.

2 Dunnington JH, Regan EF. Ziegler cautery puncture for noncicatricial entropion. Am $\mathcal{f}$ Ophthalmol 1966; 61: 1090150

3 Jones LT. The anatomy of the lower eyelid and its relation to the cause and cure of entropion. Am 7 Ophthalmol 1960; 49: 29. 4 Fox SA. Repair of senile entropion. Arch Ophthalmol 1964; 72 . 501

5 Quickert MH, Ranthbun E. Suture repair of entropion. Arch Ophthalmol 1971; 85: 304.

6 Wies FA. Spastic entropion. Trans Am Acad Ophthalmol Otolaryngol 1955; 59: 503.

7 Fox SA. The aetiology of senile entropion. Am $\mathcal{F}$ Ophthalmol 1959; 48: 607 .

8 Jones LT, Reeh MJ, Tsujimura JK. Senile entropion. $A m \mathcal{F}$ Ophthalmol 1963; 55: 463 . 